\title{
PHOTOGRAPHIC AND MANUAL EVALUATION OF GOLDEN PERCENTAGE AND RECURRENT AESTHETIC DENTAL PROPORTION IN AESTHETIC SMILES
}

\author{
Nandini T. Niranjan1, Aruna Kanaparthy², Rosaiah Kanaparthy33, Kiran H. Y4 \\ ${ }^{1}$ Reader, Department of Conservative Dentistry and Endodontics, Bapuji Dental College \& Hospital, Davangere. \\ ${ }^{2}$ Assistant Professor, Department of Operative Dentistry, College of Dentistry, Jazan University, Saudi Arabia. \\ ${ }^{3}$ Assistant Professor, Department of Periodontics, College of Dentistry, Jazan University, Jazan Saudi Arabia. \\ ${ }^{4}$ Reader, Department of Oral \& Maxillofacial Surgery, CODS, Davangere.
}

\section{ABSTRACT}

\section{BACKGROUND}

Due to increased aesthetic demands, the dentist should rely on the aesthetic principles that exist in nature so as to reproduce or integrate them in humans to mimic the essential beauty. The Golden proportion, Golden percentage and recurrent aesthetic dental proportion are some of the commonly used guidelines by the dental profession for better aesthetic proportion in dentition.

\section{AIM}

The aim of the present study was to investigate the existence of Golden Percentage and Recurrent Aesthetic Dental proportion between the widths of maxillary anterior teeth in individuals with natural aesthetic dentition.

\section{METHODS AND MATERIAL}

This study was conducted on 60 dental students with an aesthetic smile (30 males and 30 females) with ages ranging from 18 to 30 yrs. by obtaining prior consent. An impression of upper arch was made with alginate impression material and standardized facial photographs were obtained from each individual. Analysis was performed by operator on cast using Dial caliper and on photographs using Corel Draw software. The existence of Golden Percentage and Recurrent Aesthetic Dental proportion was investigated. The data was statistically analysed by student's paired ' $t$ ' test.

\section{RESULTS}

This study has shown that golden percentage is observed only in the lateral incisors and is not applicable to central incisor which showed Golden percentage of $21.7 \%$ and canine which showed $13 \%$. There was no evidence to support the existence of RED proportion.

\section{CONCLUSION}

Further studies need to be carried out on a larger population with different stereotypes to prove the existence of Golden percentage and RED proportion in the Indian population.

\section{KEYWORDS}

Golden Percentage, Recurrent Aesthetic Dental Proportion, Cast Analysis, Photographic Analysis.

HOW TO CITE THIS ARTICLE: Niranjan NT, Kanaparthy A, Kanaparthy R, et al. Photographic and manual evaluation of golden percentage and recurrent aesthetic dental proportion in aesthetic smiles. J. Evolution Med. Dent. Sci. 2016;5(38): 2267-2270, DOI: $10.14260 /$ jemds/2016/527

\section{INTRODUCTION}

One of the most important tasks in aesthetic dentistry is the creation of harmonious proportion between the widths of maxillary anterior teeth when restoring or replacing them. The essence of beauty may be the invisible background of the physically perceptive beauty that decorates the appearance of the flora and fauna and the constant equilibrium of shapes and colours that can be observed at any time in nature. ${ }^{1} \mathrm{We}$ tend to seek beauty in the face and in the smile. ${ }^{2}$ Pythagoras defined the proportional body mathematically, creating the definition of "Divine or Golden Proportion" of 1.0 to 1.168, believed to be a reference given by God because of its aesthetic excellence. ${ }^{2}$ This relationship links geometry to

Financial or Other, Competing Interest: None.

Submission 20-03-2016, Peer Review 22-04-2016,

Acceptance 28-04-2016, Published 10-05-2016.

Corresponding Author:

Dr. Rosaiah Kanaparthy,

Assistant Professor

Department of Periodontics,

College of Dentistry,

Jazan University, Jazan,

Saudi Arabia.

E-mail:drrosaiah@gmail.com

DOI: $10.14260 /$ jemds $/ 2016 / 527$
1.168 , believed to be a reference given by God because of its aesthetic excellence. ${ }^{2}$ This relationship links geometry to mathematics; hence, it has also been called the "Sacred geometry," "the magic numbers" and "the golden cut."

Lombardi was the first to propose the application of the Golden proportion in the dentistry, but he also cautioned "It has proved strong for dental use." 4 In addition he defined the idea of a repeated ratio, which implies that in an optimized dentofacial composition from the frontal aspect, the lateral to central width and the canine to lateral width are repeated in proportion. Levin pointed out that "the width of maxillary lateral incisor is in the Golden proportion to the width of the central incisor and also the width of the maxillary canine to the lateral incisor when viewing from the front. ${ }^{5}$

The Golden proportion is limited to the use of the $62 \%$ proportion and when this proportion is used the Central Incisor appears too narrow and the resulting canine is not prevalent enough. The concept of continuous proportion or repeated ratio as defined by Lombardi opens up the idea of using a continuous proportion not necessarily limited to the $62 \%$ proportion. The use of repeated proportion [Recurrent aesthetic dental proportion] gives greater flexibility. The 
dentist can use the proportion of his or her own choosing as long as the dentist is consistent while moving distally. ${ }^{6}$

Supposing that a specific tooth arrangement was in perfect Golden proportion, the ratio between the perceived widths of the maxillary anterior teeth would be $0.618: 1.0: 1.618: 1.618: 1.0: 0.618$. If all these width ratios were added together, the total would be 6.472 dividing the individual ratio values by the total yields, the percentage of width that each individual tooth would occupy the total canine to canine width, viewed from the frontal perspective. The Golden proportion has been applied to the total canine to canine width to become the "Golden Percentage" 10\%: 15\%: 25\%: $25 \%$ : $15 \%: 10 \%{ }^{7}$

\section{METHODOLOGY}

This study was carried out in Department of Conservative Dentistry and Endodontics, Bapuji Dental College and Hospital, Davangere, Karnataka, India. The inclusion criteria for this study were individuals displaying at least maxillary first premolars, no gingival recession, no hyperplastic interdental papillae, smiles showing less than $3 \mathrm{~mm}$ of the maxillary gingiva. The students were excluded if they had unpleasant dental alignment, remarkable malformations, discolorations, unpleasant fractured teeth, severe dentofacial deformities, obvious asymmetries, crowns, fixed partial dentures, fillings in upper anterior teeth.

60 patients ( 30 males and 30 females) aged between 18-30 years with aesthetic smiles were selected. Protocol of the study was explained to them and their consent was taken. Participants were made to sit upright on a dental chair and active smiles were photographed using Canon camera with $100 \mathrm{~mm}$ macro lens and Macrolite ring flash. The camera was set at 1:3 magnifications with shutter speed at 90 seconds and aperture speed at $\mathrm{f} 16$. All photographs were scanned and saved in personal computer. Later, all the photographs were imported to the Corel Draw 11 software, where the chin and the tip of the nose were eliminated and measurements of the width maxillary anterior teeth were carried out. To improve upon image accuracy, a zoom function of the program was used to allow more precise measurement from pixel to pixel. The cast analysis was also performed by taking impressions of upper arch with sterilized metal perforated trays and alginate impression material (Zelgan; Dentsply Dental Co. Ltd.). Impressions were then poured with type III dental stone and casts were analysed. The widths of maxillary anterior teeth were measured using Dial Caliper (Mitutoyo, Japan). All the measurements were recorded.

\section{RESULTS}

This study analysed the existence of Golden percentage and recurrent aesthetic dental proportion between the widths of maxillary anterior teeth in an aesthetic smile.

\section{Photographic Analysis}

The mean value and SD for Golden percentage for males and females are listed in [Table 1]. For both males and females, the lateral incisors were in Golden percentage and the values were slightly closer to the suggested percentage in comparison to the cast analysis. The mean value and the SD for RED proportion for males and females are listed in [Table 2]. The values were not constant when progressed distally. The relation between the RED proportion for males and females show no statistically significant differences according to unpaired ' $t$ ' test.

\section{Cast Analysis}

The mean values and standard deviations for the golden percentage for males and females are listed in [Table 3]. For both males and females, the right and left lateral incisors were in golden percentage (15.3-15.5); $58.3 \%$ of males and $46.5 \%$ of females lateral incisors were in Golden percentage. The canines (13) and central incisor (21.6) are slightly deviated from the suggested percentage. The mean value and SD for the RED proportion for males and females are listed in [Table 4]. The values show that the RED proportion was not constant when progressing distally with respect to RED proportion, the average value that can be set is around $73.2 \%$ for males and $75.3 \%$ for females. Unpaired sample ' $t$ ' test showed there was no statistically significant difference between males and females.

\begin{tabular}{|c|c|c|c|c|c|c|c|c|c|}
\hline \multicolumn{5}{|c|}{ Golden Percentage: Male } & \multicolumn{5}{|c|}{ Golden Percentage: Female } \\
\hline \multirow{2}{*}{ Tooth } & \multirow{2}{*}{ No. } & \multirow{2}{*}{ Mean } & \multirow{2}{*}{ SD } & \multirow{2}{*}{ Suggested } & \multirow{2}{*}{ No. } & \multirow{2}{*}{ Mean } & \multirow{2}{*}{ SD } & \multicolumn{2}{|c|}{ Male Vs Female } \\
\hline & & & & & & & & $*_{\mathrm{t}}$ & P value \\
\hline Right canine & 30 & 12.4 & 1.4 & $10 \%$ & 30 & 11.8 & 1.6 & 1.32 & $0.19 \mathrm{NS}$ \\
\hline Right lateral incisor & 30 & 15.2 & 0.9 & $15 \%$ & 30 & 16.0 & 1.4 & 2.07 & $<0.01 \mathrm{NS}$ \\
\hline Right central incisor & 30 & 22.5 & 1.1 & $25 \%$ & 30 & 22.9 & 2.0 & 1.09 & $0.28 \mathrm{NS}$ \\
\hline Left central incisor & 30 & 22.5 & 0.9 & $25 \%$ & 30 & 22.8 & 1.2 & 1.04 & $0.30 \mathrm{NS}$ \\
\hline Left lateral incisor & 30 & 15.1 & 1.1 & $15 \%$ & 30 & 15.0 & 1.7 & 0.31 & $0.76 \mathrm{NS}$ \\
\hline Left canine & 30 & 12.3 & 1.4 & $10 \%$ & 30 & 11.2 & 1.6 & 2.64 & $<0.05 \mathrm{NS}$ \\
\hline & $e N$ & Ialue & 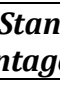 & eviatio & $P \mid$ & $\begin{array}{l}\text { grapl } \\
\text { cts }\end{array}$ & & & \\
\hline
\end{tabular}

*Unpaired ' $\mathrm{t}$ ' test

\begin{tabular}{|c|c|c|c|c|c|c|c|c|}
\hline RED Proportion: Male & \multicolumn{4}{|c|}{ RED Proportion: Female } \\
\hline Tooth & \multirow{2}{*}{ No } & \multirow{2}{*}{ Mean } & SD & \multirow{2}{*}{ No. } & \multirow{2}{*}{ Mean } & \multirow{2}{*}{ SD } & Male Vs Female \\
\cline { 3 - 10 } & & & & & & P value \\
\hline Rt. 1st premolar/canine & 30 & 63.0 & 12.0 & 30 & 67.9 & 17.6 & 1.25 & $0.22 \mathrm{NS}$ \\
\hline Rt. canine/lateral incisor & 30 & 80.7 & 11.3 & 30 & 78.1 & 11.2 & 0.92 & $0.36 \mathrm{NS}$ \\
\hline Rt. lateral incisor/central incisor & 30 & 67.4 & 7.8 & 30 & 70.0 & 5.6 & 1.51 & $0.14 \mathrm{NS}$ \\
\hline Lt lateral incisor/central incisor & 30 & 67.5 & 5.2 & 30 & 68.6 & 6.7 & 0.71 & $0.48 \mathrm{NS}$ \\
\hline Lt canine/lateral incisor & 30 & 80.5 & 11.2 & 30 & 75.7 & 10.7 & 1.70 & $0.09 \mathrm{NS}$ \\
\hline Lt 1st premolar/canine & 30 & 59.8 & 11.2 & 30 & 67.7 & 18.8 & 1.97 & $0.006 \mathrm{NS}$ \\
\hline
\end{tabular}


*Unpaired ' $\mathrm{t}$ ' test

\begin{tabular}{|c|c|c|c|c|c|c|c|c|c|}
\hline Golden Proportion: Male & \multicolumn{4}{|c|}{ Golden Proportion: Female } \\
\hline Tooth & No. & Mean & SD & Suggested & \multirow{2}{*}{ No. } & \multirow{2}{*}{ Mean } & \multirow{2}{*}{ SD } & Male Vs Female \\
\cline { 5 - 10 } & & & & & & & & P value \\
\hline Right Canine & 30 & 13.0 & 1.2 & $10 \%$ & 30 & 12.7 & 1.4 & 0.84 & $0.41 \mathrm{NS}$ \\
\hline Right Lateral incisor & 30 & 15.5 & 1.0 & $15 \%$ & 30 & 15.8 & 1.1 & 1.15 & $0.26 \mathrm{NS}$ \\
\hline Right central incisor & 30 & 21.6 & 1.2 & $25 \%$ & 30 & 21.6 & 1.2 & 0.0 & $0.99 \mathrm{NS}$ \\
\hline Left central incisor & 30 & 21.6 & 1.0 & $25 \%$ & 30 & 21.7 & 1.2 & 0.36 & $0.72 \mathrm{NS}$ \\
\hline Left Lateral incisor & 30 & 15.3 & 1.1 & $15 \%$ & 30 & 15.4 & 1.1 & 0.24 & $0.81 \mathrm{NS}$ \\
\hline Left Canine & 30 & 12.4 & 1.7 & $10 \%$ & 30 & 12.2 & 1.2 & 0.52 & $0.61 \mathrm{NS}$ \\
\hline
\end{tabular}

*Unpaired ' $\mathrm{t}$ ' test

\begin{tabular}{|c|c|c|c|c|c|c|c|c|}
\hline RED Proportion: Cast Analysis Male & \multicolumn{3}{|c|}{ RED Proportion: Cast Analysis Female } \\
\hline Tooth & \multirow{2}{*}{ No. } & \multirow{2}{*}{ Mean } & \multirow{2}{*}{ SD } & \multirow{2}{*}{ No. } & \multirow{2}{*}{ Mean } & \multirow{2}{*}{ SD } & \multicolumn{2}{|c|}{ Male Vs Female } \\
\cline { 3 - 9 } & & & & & & & P value \\
\hline Rt. 1st premolar/canine & 30 & 68.8 & 17.5 & 30 & 73.3 & 15.0 & 1.06 & $0.29 \mathrm{NS}$ \\
\hline Rt. canine/lateral incisor & 30 & 83.5 & 9.2 & 30 & 79.5 & 9.6 & 1.64 & $0.11 \mathrm{NS}$ \\
\hline Rt. lateral incisor/central incisor & 30 & 72.6 & 6.2 & 30 & 73.5 & 7.3 & 0.51 & $0.61 \mathrm{NS}$ \\
\hline Lt lateral incisor/central incisor & 30 & 71.8 & 7.0 & 30 & 71.6 & 6.3 & 0.14 & $0.89 \mathrm{NS}$ \\
\hline Lt canine/lateral incisor & 30 & 80.7 & 9.2 & 30 & 77.9 & 9.4 & 1.17 & $0.25 \mathrm{NS}$ \\
\hline Lt 1st premolar/canine & 30 & 61.6 & 12.2 & 30 & 76.1 & 11.1 & 4.78 & $<0.01 \mathrm{NS}$ \\
\hline Table 4: The Mean Value and Standard Deviation of the Cast Analysis of Red Proportion for Male and Female Subjects \\
\hline
\end{tabular}

*Unpaired ' $\mathrm{t}$ ' test

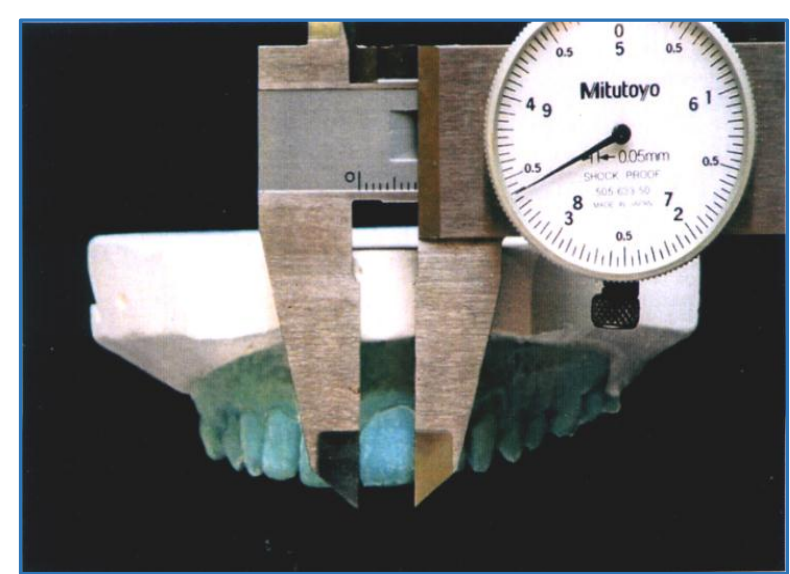

Fig. 1: Analysis of Cast Using Dial Caliper

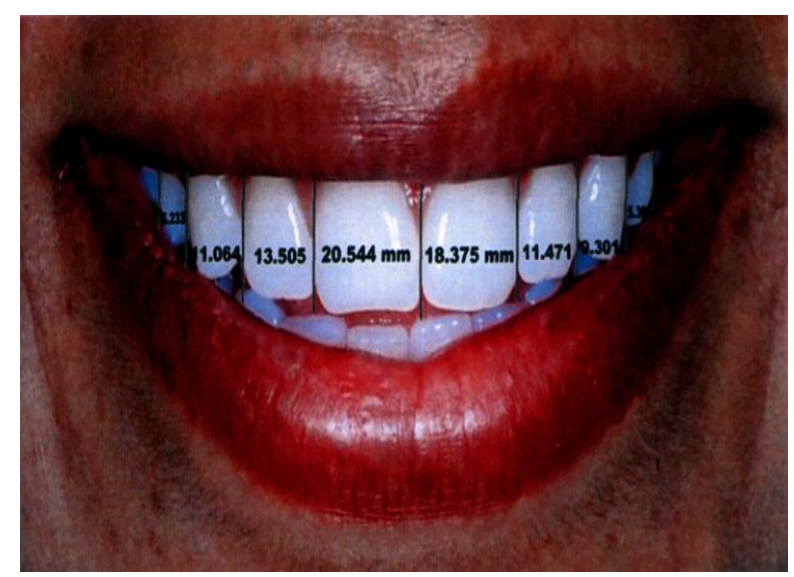

Fig. 2: Analysis of Photograph Using Corel Draw Software
The golden percentage clearly is more useful than the Golden proportion in analysing aesthetic properties of the smile, as it does not depend on the width of lateral incisors alone for its analysis. Instead it evaluates the width of each tooth for its contribution to symmetry, dominance and proportion of the entire anterior segment. Asymmetry is clearly identifiable and quantifiable in Golden percentage. In this study, the mean value for Golden percentage for central incisor is 21.6, for lateral incisor is 15.5 and for canine is $13-12$. The results are slightly different than the suggested values (10\%:15\%:25\%:25\%:15\%:10\%). The figures derived from this study are in agreement with those suggested by Snow who recommended a value of $15 \%$ as the Golden percentage only for lateral incisors. ${ }^{7}$ In cast analysis, $58.3 \%$ of male and $46.5 \%$ of female lateral incisors were in Golden percentage. These results are similar to studies done by Fayyad MA, Azam S, Rita ME et al and Azimi M.8,9,10,11 The recurrent Aesthetic Dental Proportion states that the proportion of the successive widths of the teeth as viewed from the frontal should remain constant as one moves distally. The use of RED proportion gives greater flexibility. The RED proportion can be modified to fit the face, skeletal structure and general body type of the patient. A person who is an ectomorph would be more likely to be able to use a smaller RED proportion and an endomorph would use a larger RED proportion.

The average RED value of $73.2 \%$ for males and $75.3 \%$ for females seen in this study are in close agreement with previous studies that evaluated the ratio of the width of the maxillary lateral to the central incisors in patients and reported a mean proportion of $66 \%$ to $78 \% .5,12,13$ Constant efforts are going on in developing new dental software such as the Phi Dental to determine the dental proportions digitally. Apart from the clinical grids and gauges used in mouth, we can carry out the analyses with a digital camera. ${ }^{14}$ Such developments can make our studies applicable on a

\section{DISCUSSION}


larger scale and help us in unravelling the mystery of the magical numbers.

\section{CONCLUSION}

Further studies need to be carried out on a larger population with different stereotypes to prove the existence of Golden percentage and RED proportion in the Indian population.

\section{REFERENCES}

1. Rufenacht CR. Fundamentals of aesthetics. Chicago: Quintessence 1990;9(48):67-134.

2. Castro MVM De, Santos NC, Ricardo LH. Assessment of the golden proportion in agreeable smiles. Quintessence Int 2006;37(8):597-604.

3. Wolfart S, Quaas AC. Subjective and objective perception of upper incisors. J of Oral Rehab 2006;33(7):489-95.

4. Lombardi RE. The principles of visual perception and their clinical application to denture aesthetics. J Prosthet Dent 1973;29(4):358-82.

5. Mahshid M, Khoshvaghti A, Varshosaz M, et al. Evaluation of golden proportion in individuals with an aesthetic smile. J Aesthet Restor Dent 2004;16(3):185-93.

6. Ward DH. Proportional smile design using the Recurrent Aesthetic Dental (RED) proportion. Dent Clin North Am 2001;45(1):143-54.
7. Snow SR. Aesthetic smile analysis of maxillary anterior teeth width: the golden Percentage. J Aesthet Dent 1999;11(4):177-84.

8. Ali Fayyad M, Jamani KD, Aqrabawi J. Geometric and mathematical proportions and their relations to maxillary anterior teeth. J Contemp Dent Pract 2006;7(5):62-70.

9. Azama S, Shahnawazb A, Qureshic B. Validity of aesthetic proportions in maxillary anterior teeth. POJ 2014;6(1):711.

10. Rita ME, Kinga J, Carmen B, et al. Aesthetic principles of the upper front teeth: application of golden proportion (levin) and golden percentage (snow). Acta Medica Marisiensis 2013;59(1):25-7.

11. Azimi M, Dinparvar M, Teimourian H, et al. Evaluating recurring aesthetic dental proportion (red) and golden proportion in natural dentition. Avicenna J Dent Res 2016; InPress(InPress):e30267.

12. Preston JD. The golden proportion revisited. J Aesthet Rest Dent 1993;5(6):247-51.

13. Gillen RJ, Schwartz RS, Hilton TJ, et al. An analysis of selected normative tooth proportions. Int J prosthodont 1994;7(5):410-7.

14. Paul MMC, Abraham ST. Golden proportion in denture aesthetics. Health Sciences 2013;2(1):1-8. 